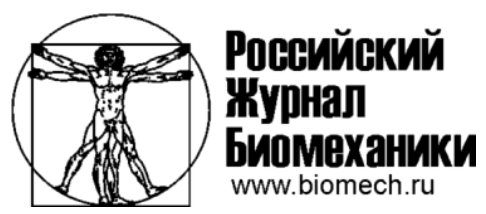

\title{
ВЛИЯНИЕ ПРИМЕНЕНИЯ БОТУЛИНОТОКСИНА НА БИОМЕХАНИЧЕСКУЮ СТРУКТУРУ ХОДЬБЫ БОЛЬНЫХ ДЕТСКИМ ЦЕРЕБРАЛЬНЫМ ПАРАЛИЧОМ
}

\author{
И.А. Матвеева ${ }^{1}$, Е.М. Дутикова², К.А. Петрушанская², \\ В.Д. Левченкова ${ }^{1}$, И.А. Сутченков ${ }^{3}$ \\ ${ }^{1}$ Научно-практический центр детской психоневрологии, 119602, Россия, Москва, Мичуринский проспект, \\ 74, e-mail: dpnb18@yandex.ru \\ ${ }^{2}$ Российский реабилитационный центр «Детство», 142031, Россия, Московская область, Домодедовский \\ район, Лукино, e-mail: info@rrcdetstvo.ru \\ ${ }^{3}$ Научно-медицинская фрирма МБН, 105120, Россия, Москва, 2-й Сыромятнический переулок, 10-6, \\ e-mail: info@mbn.ru
}

\begin{abstract}
Аннотация. Данная работа посвящена изучению влияния комплексного лечения с применением ботулинотоксина на биомеханическую структуру ходьбы детей с диплегической формой детского церебрального паралича. Исследования проводились многократно у больной детским церебральным параличом на протяжении курса традиционного восстановительного лечения, в частности до введения ботулинотоксина, а затем через 7, 11, 17 и 23 дня после введения. Исследования показали, что ботулинотерапия в сочетании с традиционными методами реабилитации приводят к неоднозначным изменениям биомеханической структуры ходьбы. С одной стороны, наблюдается резкое снижение скорости ходьбы, трансформация временной структуры шага, значительное уменьшение устойчивости, редукция угловых перемещений в суставах ног, ослабление опорной и толчковой функций конечностей. С другой стороны, отмечается некоторое снижение рекурвации в коленном суставе и эквинуса в голеностопном суставе. В целом у данной больной наблюдается ухудшение биомеханической структуры ходьбы. Авторы полагают, что необходимы более эфффективные методы формирования нового двигательного навыка, в частности фазовая электрическая стимуляция мышц или опорная стимуляция, так как коррекция проприорецептивной импульсации может в какой-то степени способствовать нормализации деятельности нарушенных структур нервной системы. С точки зрения авторов, необходимо целенаправленное формирование нового двигательного навыка непосредственно после введения ботулинотоксина.
\end{abstract}

Ключевые слова: биомеханическая структура ходьбы, ботулинотоксин, опорная и толчковая функции нижних конечностей, двигательный стереотип.

\section{ВвеДЕНИЕ}

К настоящему времени многие аспекты применения ботулинотоксина (нейротоксина белковой природы, являющегося одним из сильнейших органических ядов) уже хорошо известны. Специалисты, занимающиеся данной проблемой, останавливают свое внимание на таких вопросах, как значительное снижение

(С) Матвеева И.А., Дутикова Е.М., Петрушанская К.А., Левченкова В.Д., Сутченков И.А., 2015

Матвеева Ирина Антоновна, к.мед.н., заведующая отделом восстановительной медицины, Москва

Дутикова Елена Михайловна, директор, Лукино

Петрушанская Кира Анатольевна, к.б.н., заведующая лабораторией движения, Москва

Левченкова Вера Дмитриевна, д.мед.н., заведующая биомеханической лабораторией, Москва

Сутченков Игорь Анатольевич, инженер, Москва 
мышечного тонуса, нейрофизиологические механизмы этого снижения, медицинские показания и противопоказания к применению данного препарата, сочетание введения ботулинотоксина с другими методами реабилитации и, наконец, долговременность полученных результатов с целью выявления необходимости повторных инъекций. Ряд авторов, прослеживая влияние регулярных инъекций ботулинотоксина у больных на протяжении 1-2 лет, отмечают значительное снижение спастичности мышц у данных больных и увеличение амплитуды движений в суставах нижних конечностей [7-9, 15, 16]. Другие авторы $[10,11,13]$, исследуя эффективность применения ботулинотерапии на протяжении 3-4 лет, подвергают сомнению долговременность полученных результатов. С их точки зрения, наиболее эффективными являются только первые инъекции. После первых инъекций ботулинотоксина А наблюдается уменьшение мышечного тонуса и увеличение амплитуды движений в суставах нижних конечностей. Однако последующие инъекции в большинстве случаев давали кратковременный непосредственный результат в плане уменьшения тонуса мышц и практически не влияли на амплитуду движений в суставах нижних конечностей. Таким образом, в настоящее время имеется определенное расхождение взглядов различных специалистов даже в вопросе долговременности результатов применения ботулинотерапии. При этом из поля зрения исследователей фактически выпадает самый ранний период - от 3 до 30 дней после введения ботулинотоксина. Между тем, именно в этот период перед врачами и специалистами по лечебной физкультуре встает ряд конкретных вопросов. Во-первых, как изменяется биомеханическая структура ходьбы на протяжении этого времени? Во-вторых, через сколько дней после введения ботулинотоксина надо начинать реабилитацию? В-третьих, какие методы реабилитации являются наиболее эффективными в этот период?

Вторая проблема состоит в недостатке инструментальных исследований, другими словами, до сих пор преимущественно применяются клинические методы обследований больных: шкала спастичности Ашворта, шкала общей оценки двигательных функций (Gross Motor Function) [12, 14], исследование амплитуды движений в суставах нижних конечностей (ROM), измерение силы мышц и т.д.

C точки зрения авторов, для решения поставленных вопросов необходимо проводить инструментальное исследование ходьбы больных на протяжении курса восстановительного лечения.

Целью исследования явилось выяснение влияния введения ботулинотоксина на биомеханическую структуру ходьбы детей с диплегической формой детского церебрального паралича на самом раннем этапе, выявление механизма постепенной перестройки навыка ходьбы под воздействием данного препарата.

\section{МАТЕРИАЛЫ И МЕТОДЫ}

Для исследования биомеханической структуры ходьбы был применен комплекс, разработанный фирмой МБН «МБН-Биомеханика». Данный комплекс позволяет исследовать следующие биомеханические параметры ходьбы: основные, временные, кинематические и динамические $[5,6]$.

По подограмме определяли основные и временные параметры ходьбы, а именно длительность цикла, темп ходьбы, среднюю длину шага, расчетным путем находили среднюю скорость ходьбы, продолжительность опорной, двуопорной и переносной фаз, коэффициент ритмичности (отношение длительности переносной фазы обеих нижних конечностей) $[1,2]$.

Кинематические параметры - угловые перемещения в голеностопном, коленном и тазобедренном суставах обеих нижних конечностей - регистрировали посредством многозвенных электрогониометров. 
Динамические параметры - вертикальную $R z$, продольную $R x$ и поперечную $R y$ составляющие главного вектора опорной реакции исследовали посредством динамографической методики.

Комплексные биомеханические исследования ходьбы были проведены у 10 здоровых детей 11 лет и у больной А. с диплегической формой детского церебрального паралича (11 лет). Параметры ходьбы данной больной были сопоставлены с соответствующими параметрами ходьбы здоровых детей такого же возраста $[3,4]$. Все испытуемые ходили в произвольном темпе по горизонтальной дорожке длиной 8 м.

\section{Больная А.}

Диагноз - детский церебральный паралич, спастическая диплегия.

Клиническая картина. Походка спастическая; при ходьбе бедра приведены и ротированы внутрь. Темп ходьбы медленный, фазы опорного периода не дифференцирует, не нагружает пятки. При ходьбе отмечается рекурвация в коленном суставе. Выражены сильные раскачивания туловища во фронтальной и сагиттальной плоскостях. При ходьбе больная балансирует руками.

Больной была проведена ботулинотерапия: инъекции Диспорта в суммарной дозе 800 ЕД, по 200 ЕД в следующие мышцы: прямая мышца бедра левая, наружная широкая мышца левая, прямая мышца бедра правая, наружная широкая мышца правая.

После ботулинотерапии больная А. прошла курс традиционной реабилитации, который включал в себя массаж, занятия на тренажерах, гидрокинезотерапию.

Комплексное биомеханическое исследование ходьбы было проведено до введения ботулинотоксина и спустя 23 дня после его введения, а исследования основных, временных и динамических параметров осуществлялось многократно, в частности через 7, 11 и 17 дней после инъекций.

\section{РезУЛЬтаты}

Биомеханические исследования показывают, что у данной больной отмечается ухудшение основных параметров ходьбы по сравнению с аналогичными параметрами у здоровых детей такого же возраста (табл. 1): темп ходьбы снижается на $10 \%$ (104 шаг./мин), длина двойного шага - на $22 \%(0,9$ м), а средняя скорость передвижения - на $30 \%$ (0,78 м/с).

Определенные изменения отмечаются также и во временной структуре ходьбы (табл. 2). Прежде всего возрастает длительность опорной фазы на 14 \% на обеих ногах (70,1 \%). Напротив, продолжительность переносной фазы сокращается на 22 \% (29,9\%) по сравнению с соответствующими параметрами здоровых детей такого же возраста. Характерно значительное увеличение длительности двуопорной фазы (на 71 \%), что указывает на резкое снижение устойчивости при ходьбе.

В наибольшей степени изменены кинематические параметры ходьбы, особенно угловые перемещения в коленном суставе.

Как видно из рис. 1, при ходьбе здоровых детей кривая коленного угла состоит из двух полуволн с малой и большой амплитудой. Первая полуволна характеризует подгибание в коленном суставе, имеющее главным образом амортизационное значение (смягчение удара ноги о поверхность опоры), вторая волна отражает сгибание в суставе в переносную фазу. За каждым сгибанием следует практически полное разгибание.

При ходьбе данной больной кривая коленного угла существенно изменена. На обеих ногах отмечается значительная рекурвация в коленном суставе и резкое уменьшение сгибания в переносную фазу в коленном суставе, при этом основное сгибание сдвинуто вправо по временной оси в связи с пролонгированием опорной фазы. 
Основные параметры ходьбы здоровых детей 10-11 лет и больной А. (диагноз: диплегическая форма детского церебрального паралича)

\begin{tabular}{|c|c|c|c|c|}
\hline \multirow{2}{*}{$\begin{array}{c}\text { Характеристики } \\
\text { ходьбы }\end{array}$} & Норма $(n=10)$ & \multicolumn{3}{|c|}{ Больная } \\
\cline { 1 - 5 } & $M \pm m$ & $M$ & \% к норме & $p$ \\
\hline Длительность цикла, с & $1,04 \pm 0,01$ & 1,15 & 111 & $<0,05$ \\
\hline Длина двойного шага, м & $1,15 \pm 0,02$ & 0,90 & 78 & $<0,05$ \\
\hline Скорость ходьбы, м/с & $1,11 \pm 0,02$ & 0,78 & 70 & $<0,05$ \\
\hline Темп ходьбы, шаг./мин & $115 \pm 1$ & 104 & 90 & $<0,05$ \\
\hline
\end{tabular}

Таблиия 2

Временные характеристики ходьбы здоровых детей 10-11 лет и больной А. (диагноз: диплегическая форма детского церебрального паралича)

\begin{tabular}{|c|c|c|c|c|c|c|c|}
\hline \multirow{3}{*}{ Параметры } & \multirow{3}{*}{$\begin{array}{c}\begin{array}{c}\text { Норма } \\
(n=10)\end{array} \\
M \pm m\end{array}$} & \multicolumn{6}{|c|}{ Больная } \\
\hline & & \multicolumn{3}{|c|}{ Левая нога } & \multicolumn{3}{|c|}{ Правая нога } \\
\hline & & $M$ & $\begin{array}{c}\% \text { к } \\
\text { норме } \\
\end{array}$ & $p$ & $M$ & $\begin{array}{c}\% \text { к } \\
\text { норме } \\
\end{array}$ & $p$ \\
\hline Длительность опорной фазы, \% & $61,7 \pm 0,9$ & 70,1 & 114 & $<0,05$ & 70,2 & 114 & $<0,05$ \\
\hline Длительность переносной фазы, \% & $38,3 \pm 0,6$ & 29,9 & 78 & $<0,05$ & 29,8 & 78 & $<0,05$ \\
\hline Длительность двуопорной фазы, \% & $11,8 \pm 0,6$ & 20,0 & 169 & $<0,05$ & 20,3 & 172 & $<0,05$ \\
\hline Коэффициент ритмичности & $0,99 \pm 0,01$ & 0,99 & 100 & $>0,05$ & & - & \\
\hline
\end{tabular}

Кривая угла в голеностопном суставе при ходьбе здоровых детей имеет четыре экстремальных значения, из которых два соответствуют подошвенному сгибанию в начале и в конце опорной фазы, а два - тыльному сгибанию во время переката стопы через носок и в первой половине переносной фазы.

Поскольку у больной наблюдается эквинусное положение стопы, вся кривая голеностопного угла резко смещается вниз относительно нулевой линии. Вследствие эквинусного положения в правом голеностопном суставе отмечается значительное увеличение первого подошвенного сгибания, в то время как первое тыльное сгибание снижено по амплитуде и длительности. Второе подошвенное сгибание уменьшено, что указывает на слабость отталкивания ноги от опорной поверхности. На левой ноге также наблюдается эквинусное положение стопы, поэтому начало подошвенного сгибания приходится на отрицательные значения; тыльное сгибание резко снижено и пролонгировано на большую часть опорной фазы, второе подошвенное и второе тыльное сгибания отсутствуют.

Кривая угла в тазобедренном суставе при ходьбе в норме имеет три экстремальных значения: два из них соответствуют сгибанию в суставе, одно разгибанию. Каждый цикл начинается со сгибания, которое удерживается в течение интервала опоры на пятку, далее происходит разгибание в суставе, достигающее максимального значения в середине интервала опоры на носок. Затем снова наступает сгибание в переносную фазу, которое лишь в конце цикла сменяется небольшим разгибанием. 
$\begin{array}{lc}\text { Левая нижняя } & \text { Правая нижняя } \\ \text { конечность } & \text { конечность }\end{array}$

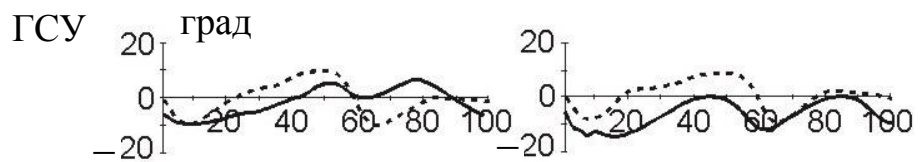

КУ

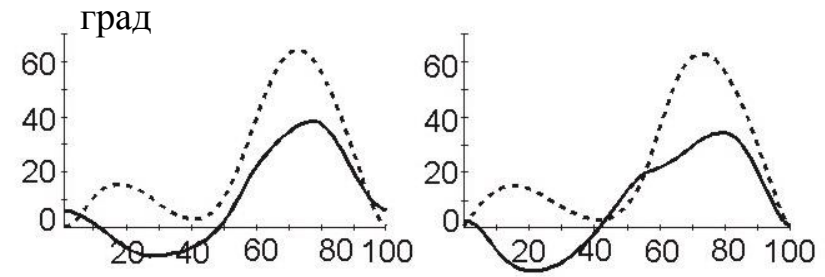

ТБУ
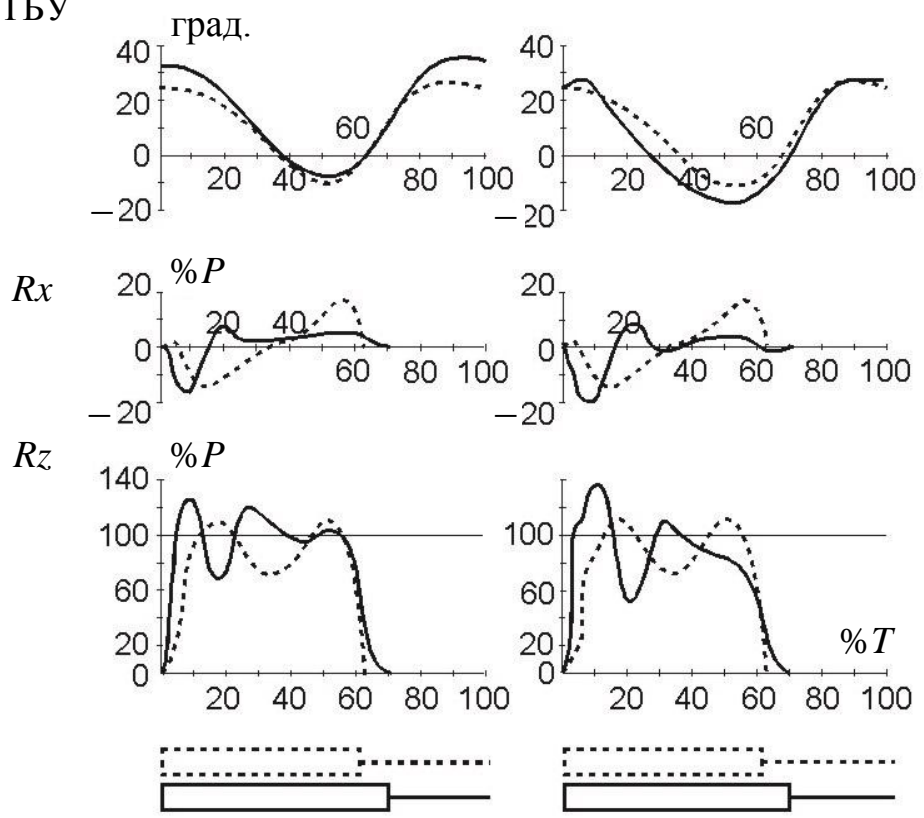

Рис. 1. Кинематические (град) и динамические (\% к весу тела $P$ ) параметры при ходьбе здоровых детей 10-11 лет и больной А. (диагноз: диплегическая форма детского церебрального паралича: ГСУ - голеностопный угол; КУ - коленный угол; ТБУ - тазобедренный угол; $R x$ - продольная; $R z$ - вертикальная составляющие опорной реакции; $T$ - цикл шага. Пунктирная линия - здоровые дети, сплошная линия - больная. Под графиками подограмма

При ходьбе данной больной сохраняются основные элементы угла в тазобедренном суставе. Однако отмечается незначительное увеличение амплитуды движений в обоих тазобедренных суставах за счет увеличения угла сгибания как в опорную, так и в переносную фазы.

Таким образом, изучение кинематических параметров ходьбы данной больной отчетливо демонстрирует, что неправильная поза нижних конечностей, наблюдаемая при стоянии, сохраняется и в процессе локомоции.

Кривые составляющих опорных реакций дают представление о динамической характеристике ходьбы. В данном исследовании регистрировали лишь две из них вертикальную и продольную составляющие.

Вертикальная составляющая опорной реакции (кривая $R z$ ) у здоровых детей имеет двугорбый вид с четко выраженным передним толчком, задним толчком и минимумом между ними. 
Продольная составляющая опорной реакции (кривая $R x$ ) у здоровых детей представлена двумя противоположно направленными максимумами, из которых отрицательный максимум соответствует переднему толчку, а положительный - заднему толчку.

У данной больной выявлены существенные нарушения также и в динамических параметрах ходьбы. Несмотря на некоторые отличия, для вертикальной составляющей $R z$ обеих нижних конечностей характерно существенное увеличение амплитуды переднего толчка (до 140 \%), значительное снижение минимума - до 53 \%, наличие нескольких максимумов в области заднего толчка с постоянно снижающейся амплитудой. В кривой продольной составляющей $R x$ отмечается увеличение переднего толчка на обеих ногах, резкое ослабление и пролонгирование заднего толчка на левой ноге и отсутствие данного толчка на правой ноге.

Полученные данные свидетельствуют о том, что по сравнению со здоровыми детьми соответствующего возраста у данной больной отмечается выраженное изменение биомеханической структуры ходьбы, а именно: значительное снижение средней скорости передвижения вследствие укорочения длины шага и в меньшей степени уменьшения темпа ходьбы, трансформация временной структуры шага, резкое снижение устойчивости при ходьбе, редукция амплитуды движений в коленном и голеностопном суставах, эквинусное положение стопы, деформация всех составляющих опорной реакции, ослабление толчковой функции обеих нижних конечностей.

На протяжении курса восстановительного лечения происходит определенная трансформация биомеханических параметров ходьбы. Данные по изменению основных параметров ходьбы приведены в табл. 3, а трансформация динамических параметров ходьбы представлена на рис. 2-4.

Через неделю после введения ботулинотоксина скорость ходьбы не изменяется, однако темп ходьбы повышается со 104 до 108 шаг./мин, и, напротив, незначительно укорачивается длина двойного шага - с 0,9 до 0,87 м. В кривой вертикальной составляющей $R z$ на левой ноге наблюдается возрастание усилия переднего толчка и незначительное снижение величины усилия заднего толчка. При этом правая нога попрежнему остается более пораженной. В кривой продольной составляющей $R x$ отмечается только снижение величины переднего толчка.

Таблиия 3

Основные параметры ходьбы больной А. (диагноз: диплегическая форма детского церебрального паралича) на протяжении курса восстановительного лечения

\begin{tabular}{|c|c|c|c|c|c|c|c|c|c|}
\hline \multirow{2}{*}{ Параметры } & $\begin{array}{c}\text { До } \\
\text { начала } \\
\text { лечения }\end{array}$ & \multicolumn{2}{|c|}{7 дней } & \multicolumn{2}{|c|}{11 дней } & \multicolumn{2}{|c|}{17 дней } & \multicolumn{2}{|c|}{23 дня } \\
\cline { 2 - 27 } & $M$ & $M$ & $\begin{array}{c}\% \text { к } \\
\text { до }\end{array}$ & $M$ & $\begin{array}{c}\% \text { к } \\
\text { до }\end{array}$ & $M$ & $\begin{array}{c}\% \text { к } \\
\text { до }\end{array}$ & $M$ & $\begin{array}{c}\% \text { к } \\
\text { до }\end{array}$ \\
\hline Длительность цикла, с & 1,15 & 1,11 & 97 & 1,32 & 115 & 1,46 & 127 & 1,76 & 153 \\
\hline $\begin{array}{c}\text { Длина двойного } \\
\text { шага, м }\end{array}$ & 0,90 & 0,87 & 97 & 0,87 & 97 & 0,83 & 92 & 0,81 & 90 \\
\hline Скорость ходьбы, м/с & 0,78 & 0,78 & 100 & 0,66 & 85 & 0,57 & 73 & 0,46 & 59 \\
\hline Темп, шаг./мин & 104 & 108 & 104 & 91 & 88 & 82 & 79 & 68 & 65 \\
\hline
\end{tabular}




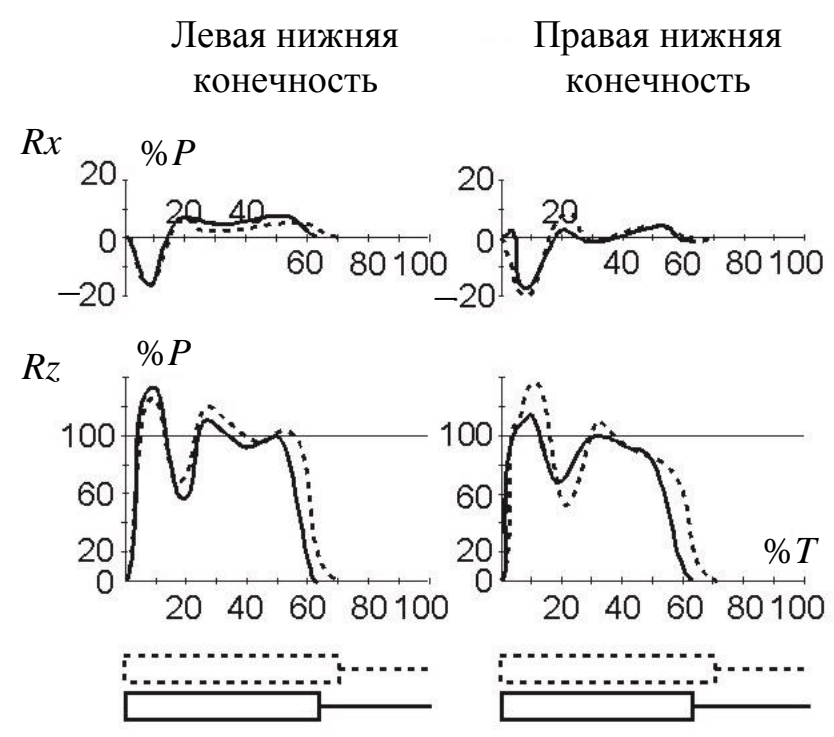

Рис. 2. Динамические (\% к весу тела) параметры при ходьбе больной А. (диагноз: диплегическая форма детского церебрального паралича) до введения ботулинотоксина и через 7 дней. Пунктирная линия - до введения ботулинотоксина, сплошная линия - через 7 дней. Остальные обозначения как на рис. 1

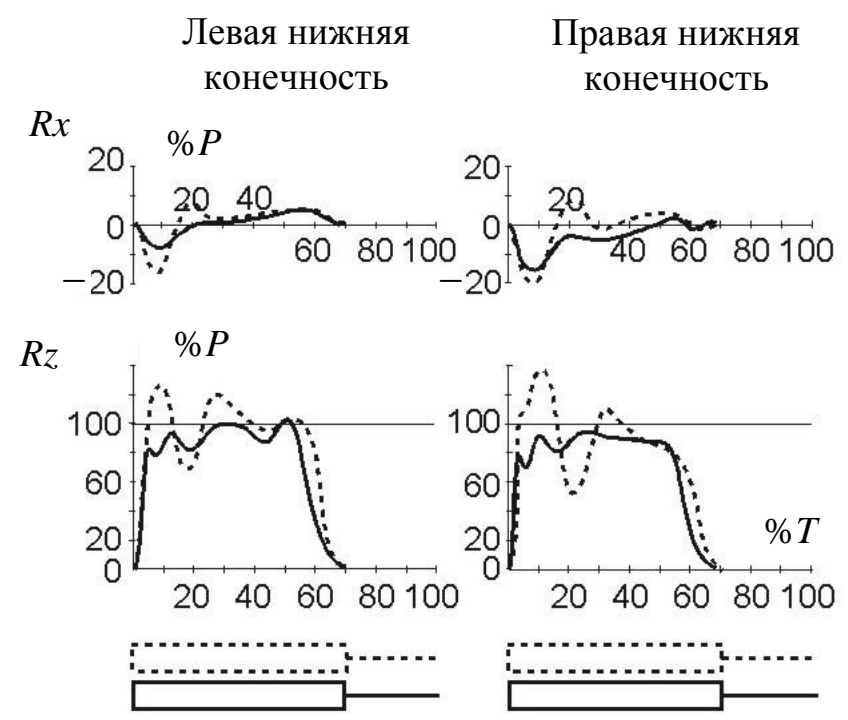

Рис. 3. Динамические (\% к весу тела) параметры при ходьбе больной А. (диагноз: диплегическая форма детского церебрального паралича) до введения ботулинотоксина и через 11 дней. Пунктирная линия - до введения ботулинотоксина, сплошная линия - через 11 дней. Остальные обозначения как на рис. 1

Через 11 дней после введения ботулинотоксина происходят более серьезные изменения биомеханических параметров ходьбы.

Прежде всего впервые снижается скорость ходьбы (на $15 \%$ ), причем основной механизм этого снижения - уменьшение темпа ходьбы (со 108 до 91 шаг./мин), при этом длина шага остается без изменений. Также наблюдается определенная трансформация динамических параметров. Значительно снижается величина 
$\begin{array}{cc}\text { Левая нижняя } & \text { Правая нижняя } \\ \text { конечность } & \text { конечность }\end{array}$
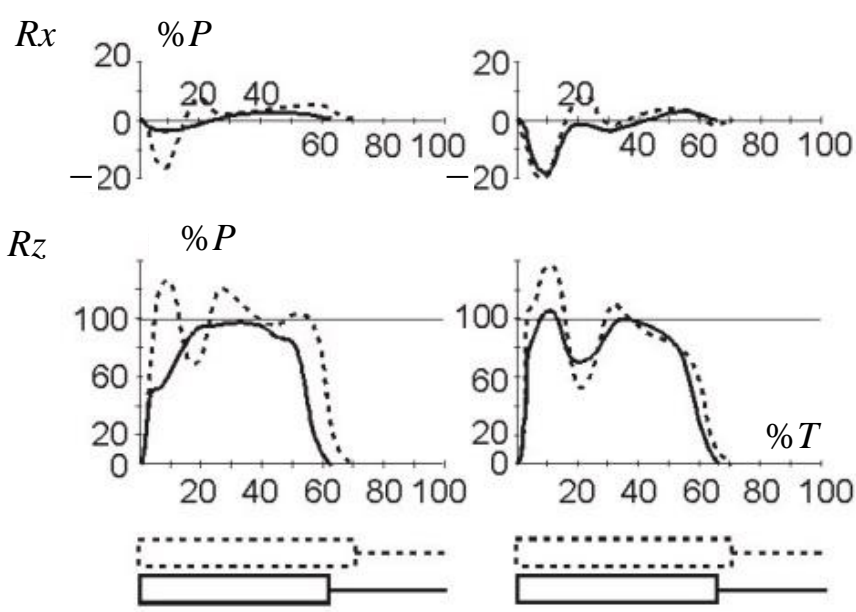

Рис. 4. Динамические (\% к весу тела) параметры при ходьбе больной А. (диагноз: диплегическая форма детского церебрального паралича) до введения ботулинотоксина и через 17 дней. Пунктирная линия - до введения ботулинотоксина, сплошная линия - через 17 дней. Остальные обозначения как на рис. 1

переднего толчка вертикальной составляющей $R z$ на обеих ногах, но в большей степени с правой стороны. На правой ноге практически исчезает задний толчок, на левой ноге кривая $R z$ приобретает статический характер, т.е. имеется несколько слабо выраженных толчков с нивелированными максимумами. Также на левой ноге резко ослаблен передний толчок продольной составляющей $R x$ опорной реакции. Таким образом, через 11 дней после введения ботулинотоксина изменение динамических параметров ходьбы представляет собой типичную картину двустороннего вялого пареза с преимущественным поражением правой нижней конечности.

Через 17 дней наблюдается дальнейшее снижение средней скорости передвижения до 0,57 м/с, темп ходьбы уменьшается до 82 шаг./мин, а длина двойного шага - до 0,83 м.

Также усугубляется нарушение динамических параметров ходьбы. Четко прослеживаются две тенденции: во-первых, поражение приобретает односторонний характер, а во-вторых, более пораженной становится левая нога. На левой ноге вертикальная составляющая $R z$ опорной реакции принимает треугольную форму, при этом вся кривая располагается ниже уровня веса тела. Согласно литературным данным, кривая вертикальной составляющей $R z$ принимает треугольную форму только в тех случаях, когда больные ходят с дополнительной опорой [3]. В данном случае больная ходит с поддержкой за руку, вследствие чего у нее значительно возрастает влияние дополнительной опоры. На левой ноге у больной практически исчезают передний и задний толчки продольной составляющей $R x$ опорной реакции. На правой ноге сохраняется двугорбый характер кривой $R z$, однако величина обоих толчков не выходит за пределы уровня веса тела.

Через 23 дня больной было проведено полное биомеханическое обследование. Цель данного обследования - выявить влияние комплексного лечения, сочетающего введение ботулинотоксина с курсом традиционной реабилитации. 
В результате комплексного лечения у больной происходят следующие изменения. Средняя скорость ходьбы уменьшается на $41 \%(0,46$ м/с) по сравнению с первоначальными данными, при этом темп снижается на $35 \%$ (68 шаг./мин), а длина двойного шага - на $10 \%(0,81$ м).

Ухудшается также и временная структура шага (табл. 4). В частности, возрастает длительность опорной фазы на $4 \%(72,9 \%)$, и в особенности двуопорной фазы (на $12 \%$ на левой ноге и на $9 \%$ - на правой ноге), и уменьшается продолжительность переносной фазы (соответственно на 9 и 5 \%). (рис. 5).

Для кинематических параметров ходьбы типичны следующие особенности

Наибольшие изменения отмечаются в кривой голеностопного угла. На левой ноге практически исчезают основные фазы движения в голеностопном суставе. На правой ноге наблюдается уменьшение величины первого подошвенного сгибания, некоторое повышение первого тыльного сгибания и появление второго подошвенного сгибания.

В кривой правого коленного угла наблюдается уменьшение рекурвации в коленном суставе, в кривой левого коленного угла рекурвация практически исчезает. На правой ноге амплитуда движений в коленном суставе снижена; сгибание происходит очень медленно, его начало приурочено к середине опорной фазы. Напротив, сокращено время следующего за ним разгибания.

Наконец, в кривой тазобедренного угла отмечается резкое снижение амплитуды движений вследствие редукции как угла сгибания в опорную фазу, так и угла разгибания. Снижение амплитуды движений в левом тазобедренном суставе является более выраженным по сравнению с аналогичным правым.

Также существенно трансформируются динамические параметры ходьбы (рис. 5). На левой ноге крайне слабо выражен минимум вертикальной составляющей $R z$ опорной реакции. Кривая фактически принимает трапециевидную форму, с резко затянутыми передним и задним фронтами. Правая нога в данном случае является менее пораженной: величина переднего толчка превышает уровень веса тела, задний толчок резко ослаблен, минимум слабо выражен. В кривой продольной составляющей $R x$ на обеих нижних конечностях происходит резкое снижение амплитуды переднего толчка и менее значительная редукция заднего толчка.

Таблициа 4

Временные параметры ходьбы $(M \pm m)$ больной А. (диагноз: диплегическая форма детского церебрального паралича) до и после курса восстановительного лечения

\begin{tabular}{|l|c|c|c|c|c|c|c|c|}
\hline \multirow{2}{*}{\multicolumn{1}{|c|}{ Параметры }} & \multicolumn{4}{|c|}{ Левая нога } & \multicolumn{5}{c|}{ Правая нога } \\
\cline { 2 - 10 } & $\begin{array}{c}\text { До } \\
\text { курса }\end{array}$ & $\begin{array}{c}\text { После } \\
\text { курса }\end{array}$ & $\%$ & $p$ & $\begin{array}{c}\text { До } \\
\text { курса }\end{array}$ & $\begin{array}{c}\text { После } \\
\text { курса }\end{array}$ & $\%$ & $p$ \\
\hline $\begin{array}{l}\text { Длительность } \\
\text { опорной фазы, \% }\end{array}$ & $70,1 \pm 1,0$ & $72,9 \pm 1,2$ & 104 & $>0,05$ & $70,2 \pm 1,9$ & $71,7 \pm 0,4$ & 102 & $>0,05$ \\
\hline $\begin{array}{l}\text { Длительность } \\
\text { переносной фазы, \% }\end{array}$ & $29,9 \pm 1,0$ & $27,1 \pm 1,2$ & 91 & $>0,05$ & $29,8 \pm 1,9$ & $28,3 \pm 0,4$ & 95 & $>0,05$ \\
\hline $\begin{array}{l}\text { Длительность } \\
\text { двуопорной фазы, \% }\end{array}$ & $20,0 \pm 1,3$ & $22,4 \pm 0,6$ & 112 & $>0,05$ & $20,3 \pm 1,1$ & $22,2 \pm 1,1$ & 109 & $>0,05$ \\
\hline $\begin{array}{l}\text { Коэффициент } \\
\text { ритмичности }\end{array}$ & $1,00 \pm 0,03$ & $0,96 \pm 0,02$ & 96 & $>0,05$ & & & - & \\
\hline
\end{tabular}




$\begin{array}{cc}\text { Левая нижняя } & \text { Правая нижняя } \\ \text { конечность } & \text { конечность }\end{array}$
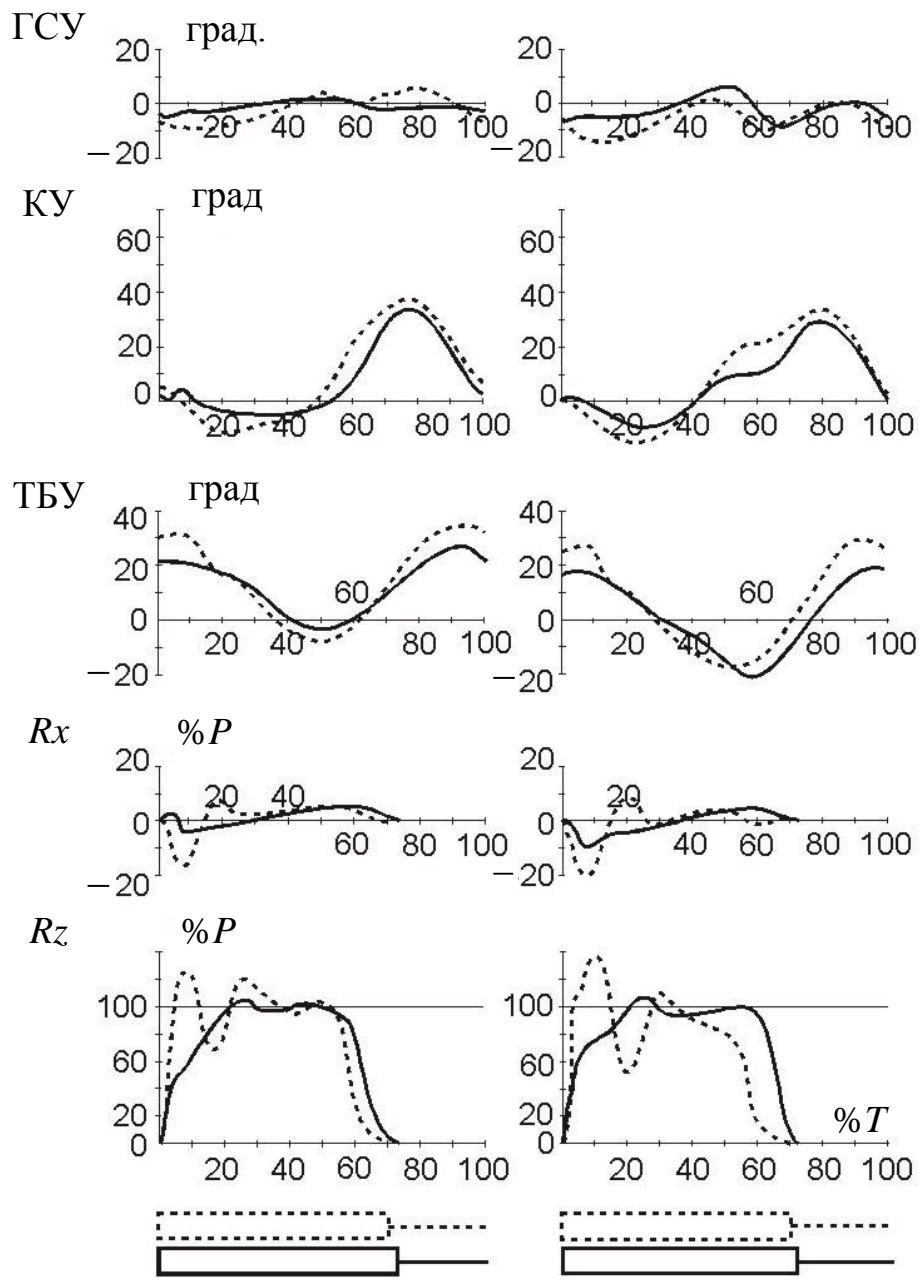

Рис. 5. Кинематические (град) и динамические (\% к весу тела) параметры при ходьбе больной А. (диагноз: диплегическая форма детского церебрального паралича) до введения ботулинотоксина и после курса восстановительного лечения. Пунктирная линия - до введения ботулинотоксина, сплошная линия -

после курса восстановительного лечения. Остальные обозначения как на рис. 1

Таким образом, ботулинотерапия в сочетании с методами традиционной реабилитации приводит к неоднозначным изменениям биомеханической структуры ходьбы у данной больной. С одной стороны, происходит резкое снижение скорости ходьбы, трансформация временной структуры шага, значительное снижение устойчивости при ходьбе, редукция угловых перемещений в суставах обеих ног, ослабление опорной и толчковой функций нижних конечностей. С другой стороны, достигается некоторое уменьшение рекурвации в коленном суставе и эквинуса в голеностопном суставе. В целом же, несмотря на некоторые положительные результаты, можно констатировать, что у данной больной отмечается отчетливое ухудшение биомеханической структуры ходьбы. 


\section{ОБСУЖДЕНИЕ РЕЗУЛЬТАТОВ}

С точки зрения авторов, наибольший интерес представляют следующие факты. Во-первых, на протяжении всего курса происходит перестройка локомоторного стереотипа, однако она не носит целенаправленного характера. Во-вторых, ухудшение функции передвижения наступает примерно через 11 дней после введения ботулинотоксина и продолжается до конца курса лечения. В-третьих, в результате комплексного лечения с применением ботулинотерапии у данной больной наблюдается непропорциональное изменение темпа и длины шага, в частности темп снижается в значительно большей степени по сравнению с длиной шага.

По мнению авторов, наибольший интерес представляет именно первый факт. Конечной целью реабилитации больных с поражением опорно-двигательного аппарата является формирование навыка ходьбы, приближающегося к нормальному. О формировании локомоторного навыка в результате курса реабилитации можно говорить только в том случае, если у больных имеют место следующие положительные изменения биомеханической структуры ходьбы: увеличение амплитуды движений во всех суставах нижних конечностей, повышение устойчивости, рост опорной и толчковой функций нижних конечностей, бо́льшая концентрация мышечных усилий в определенные фазы локомоторного цикла. Итогом этих положительных изменений является повышение средней скорости ходьбы, сопровождающееся снижением энерготрат.

У данной больной не только не происходит формирования нового двигательного стереотипа, а, скорее, осуществляется противоположный процесс - его постоянное разрушение. На протяжении 23 дней у больной неоднократно меняется сторона поражения, значительно снижается устойчивость (увеличение длительности двуопорной фазы, треугольная форма вертикальной составляющей $R z$ на левой ноге), ухудшается межконечностное взаимодействие (повышение минимума вертикальной составляющей $R z$ опорной реакции), резко ослабляются опорная и особенно толчковая функции нижних конечностей. Полученные результаты свидетельствуют о том, что традиционные методы реабилитации являются неэффективными для данной больной.

Следовательно, необходимы более эффективные методы формирования нового локомоторного навыка.

Одним из таких методов является искусственная коррекция движений при ходьбе посредством фазовой электрической стимуляции мышц. С помощью фазовой электрической стимуляции становится возможным улучшение функционального состояния мышц, осуществление коррекции движений в определенные фазы шага и в итоге выработка у больных более правильного двигательного стереотипа. Другим чрезвычайно эффективным методом является опорная стимуляция. Коррекция проприорецептивной импульсации может в какой-то степени способствовать нормализации деятельности нарушенных структур нервной системы, контролирующих моторику, а также замедлить или предотвратить развитие патологических изменений у детей с различными формами детского церебрального паралича. С точки зрения авторов, необходимо целенаправленно формировать новый двигательный навык непосредственно после введения ботулинотоксина, не дожидаясь картины развития тяжелого вялого парапареза, как это наблюдается у данной больной.

Наши дальнейшие исследования показали, что вне зависимости от выбранной тактики лечения на 10-11-й день после введения ботулинотоксина у всех больных наблюдается отчетливое ухудшение биомеханической структуры ходьбы. Основной особенностью этого ухудшения является резкое снижение скорости ходьбы, уменьшение амплитуды движений во всех суставах и нивелирование заднего толчка 
вертикальной составляющей $R z$ опорной реакции, т.е. резкое ослабление толчковой функции нижних конечностей. Тем не менее при сочетании ботулинотерапии с опорной стимуляцией длительность данного ухудшения составляет всего 1-2 дня, а затем происходит заметное и довольно быстрое возрастание опорной и толчковой функций обеих нижних конечностей, увеличение амплитуды движений в суставах ног, значительное повышение устойчивости при ходьбе, что, в конечном счете, приводит к некоторому повышению скорости ходьбы.

Полученные данные говорят о целесообразности отслеживания клинических и биомеханических результатов ботулинотерапии не только в отдаленные сроки (90 дней и более), но, в первую очередь, в более ранние сроки, поскольку от правильно выбранной тактики реабилитации именно в этот период зависит конечный эффект лечения.

\section{Выводы}

1. Сочетание применения ботулинотоксина с традиционными методами реабилитации приводит к неоднозначным изменениям биомеханической структуры ходьбы: незначительное уменьшение рекурвации в коленном суставе и эквинуса в голеностопном суставе сопровождается резким снижением скорости и темпа передвижения, укорочением длины шага, уменьшением амплитуды угловых перемещений во всех суставах нижних конечностей, ослаблением опорной и особенно толчковой функций нижних конечностей.

2. Сочетание применения ботулинотоксина с традиционными методами реабилитации приводит к ухудшению биомеханической структуры ходьбы примерно через 10-11 дней после инъекций, однако это ухудшение не носит направленного характера.

3. При применении ботулинотоксина необходимы более эффективные способы формирования нового двигательного стереотипа, в частности фазовая электрическая стимуляция мышц при ходьбе, что позволяет улучшить функцию ослабленных мышц, осуществить коррекцию движений и в итоге выработать более правильный двигательный стереотип.

4. Целенаправленное формирование двигательного навыка с применением инновационных технологий (опорная стимуляция, фазовая электрическая стимуляция и т.д.) необходимо начинать непосредственно после введения ботулинотоксина, что позволит предотвратить развитие вялого пареза.

5. Необходимо отслеживать биомеханическую структуру ходьбы не только каждые три месяца после введения ботулинотоксина, но и в самые ранние сроки, что позволяет правильно определить тактику лечения больных с диплегической формой детского церебрального паралича.

\section{СПИСОК ЛИТЕРАТУРЫ}

1. Витензон А.С. Закономерности нормальной и патологической ходьбы человека. - М.: Зеркало-М, 1998. - 272 c.

2. Витензон А.С., Миронов Е.М., Петрушанская К.А., Скоблин А.А. Искусственная коррекция движений при патологической ходьбе. - М.: Зеркало, 1999. - 503 с. 
3. Витензон А.С., Петрушанская К.А. От естественного к искусственному управлению локомоцией / Науч.-мед. фирма МБН. - М., 2003. - 447 с.

4. Витензон А.С., Петрушанская К.А., Спивак Б.Г., Матвеева И.А., Гриценко Г.П., Сутченков И.А. Особенности биомеханической структуры ходьбы у здоровых детей разного возраста // Российский журнал биомеханики. - 2013. - Т. 17, № 1 (59). - С. 78-94.

5. Скворцов Д.В. Диагностика двигательной патологии инструментальными методами. Анализ походки. Стабилометрия / Науч.-мед. фирма МБН. - М., 2007. - 638 с.

6. Скворцов Д.В. Клинический анализ движений, анализ походки / Науч.-мед. фирма МБН. - М., 1996. - 344 c.

7. Baker R., Jasinski M., Masiag-Tymeccka I., Michalowska-Mrozek J., Bonikowski M., Carr L., MacLean J., Lin J.P., Lynch B., Theologis T., Wendorff J., Eunson P., Cosgrove A. Botulinum toxin treatment of spasticity in diplegic cerebral palsy: a randomized, double-blind, placebo-controlled, dose-ranging study // Dev. Med. Child Neurol. - 2002. - Vol. 44. - P. 666-675. DOI:10.1111/j.1469-8749.2002.tb00268.x

8. Bjornson K., Hays R., Graubert C., Price R., Won F., McLaughlin J.F., Cohen M. Botulinum toxin for spacticity in children with cerebral palsy: a comprehensive evaluation // Pediatrics. - 2007. - Vol. 120. P. 49-58. DOI:10.1542/peds.2007-0016

9. Boyd R.N., Hays R.M. Current evidence for the use of botilinum toxin type A in the management of children with cerebral palsy: a systematic review // Eur. J. Neurol. - 2001. - Vol. 8 (suppl. 5). - P. 1-20. DOI:10.1046/j.1468-1331.2001.00034.x

10. Forssberg H., Tedroff K.B. Botulinum toxin treatment in cerebral palsy: intervention with poor evaluation? // Dev. Med. Child. Neurol. - 1997. - Vol. 39. - P. 635-640.

11. Gough M., Fairhurst C., Shortland A.P. Botulinum toxin and cerebral palsy: time for reflection? // Dev. Med. Child Neurol. - 2005. - Vol. 47. - P. 709-712. DOI:10.1111/j.1469-8749.2005.tb01062.x

12. Palisano R., Rosenbaum P., Walter S., Russel D., Wood E., Galuppi B. Development and reliability of a system to classify gross motor function in children with cerebral palsy // Dev. Med. Child Neurol. - 1997. Vol. 39. - P. 214-223.

13. Reddihough D.S., King J.A., Coleman G.J., Fosang A., McCoy A.T., Thomason P., Graham H.K. Functional outcome of botulinum toxin A injections to the lower limbs in cerebral palsy // Dev. Med. Child Neurol. - 2002. - Vol. 44. - P. 820-827.

14. Russel D., Rosenbaum P., Gadman D.T., Gowland C, Hardy S., Jarvis S. The gross motor function: a means to evaluate the effects of physical therapy // Dev. Med. Child Neurol. - 1989. - Vol. 31. P. 341-352.

15. Satila H., Iisalo T., Pietikainen T., Seppanen R.L., Salo M., Koivikko M., Autti-Ramo I., Haataja R. Botulinum toxin treatment of spastic equinus in cerebral palsy: a randomized trial comparing two injection sites // Am. J. Phys. Med. Rehabil. - 2005. - Vol. 84. - P. 355-365.

16. Scholtes V.A., Dallmeijer A.J., Knol D.L., Speth L.A., Maathuis C.G., Jongerius P.H., Becher J.G. Effect of multilevel botulinum toxin A and comprehensive rehabilitation in gait in cerebral palsy // Pediatr. Neurol. 2007. - Vol. 36. - P. 30-39. DOI:10.1016/j.pediatrneurol.2006.09.010

\section{INFLUENCE OF APPLICATION OF BOTULINUM TOXIN ON BIOMECHANICAL STRUCTURE OF WALKING IN PATIENTS WITH INFANTILE CEREBRAL PALSY}

\section{I.A. Matveeva, E.M. Dutikova, K.A. Petrushanskaya, V.D. Levchenkova, I.A. Sutchenkov (Moscow, Russia)}

This work is devoted to study of influence of complex treatment with application of botulinum toxin on biomechanical structure of walking of children with displegic form of infantile cerebral palsy. Investigation have been carried out many times in patient with diplegic form of infantile cerebral palsy, in particular, before injection of botulinum toxin and then in 7,11, 17, and 23 days after injection. Our investigations showed that botulinum toxin therapy in combination with the traditional methods of rehabilitation led to the ambiguous 
changes of the biomechanical structure of walking. On the one hand, the following events take place in the biomechanical structure of walking: considerable reduction of mean walking velocity, transformation of the temporal structure of walking, remarkable diminution of stability, decrease of angular displacements at the joints of both of the extremities, weakening of the support and push functions of the extremities. On the other hand, some reduction of recurvation at the knee joint and equinus at the ankle joint is observed. As a whole, worsening of the biomechanical structure of walking may be seen in this patient. Authors suppose, that more effective ways are necessary for formation of the new locomotor stereotype, in particular, phase electrical stimulation of muscles or restoration of the motional functions, as correction of the proprioreceptive pulsation may promote normalization of activity of the distorted structures of the nervous system. Authors consider, that purposeful formation of the new locomotor stereotype is necessary directly after botulinum toxin injection.

Key words: biomechanical structure of walking, botulinum toxin, support and push function of the lower extremities, locomotor stereotype.

Получено 29 июня 2015 